http://www.jfas.info

\title{
MODELLING AND VERIFICATION OF THREE DOF ENGINE MOUNT SYSTEM
}

\author{
M. F. M. Yusoff*, K. Hudha, Z. Kadir, V. Rao, N. H. Ameer and S. A. F. M. Ishak \\ Department of Mechanical Engineering, Faculty of Engineering, National Defence University \\ of Malaysia, Faculty of Engineering, 57000 Kuala Lumpur, Malaysia
}

Published online: 10 September 2017

\begin{abstract}
This paper presents the modelling and validation of three degree of freedom of engine mount system. The engine mounting system successful to isolate the driver and passenger from the noise and vibration, but there is a need to improve the performance of engine mount system due to current modern car design which required lighter car body, higher speed and larger power-intensive engine. The passive rubber has been modelled as spring and damper in parallel. Based on Newton's Second Law, the mathematical equation has been derived out and implemented into MATLAB Simulink for the validation purposes. A real experimental data from engine mount system has been used as the benchmark in this study. The response of the acceleration from the real system has been compared with the simulation result. Percentage difference of 3.9 to $5 \%$ has been obtained for the simulated model as compared to the real experimental result.
\end{abstract}

Keywords: engine mount; validation; three degree of freedom.

Author Correspondence, e-mail: fazli@upnm.edu.my

doi: http://dx.doi.org/10.4314/jfas.v9i3s.32

\section{INTRODUCTION}

The vibration characteristic of the vehicle is one of the most significant factors in ride and 
comfort. An engine is one of the most dominant noise and vibration sources in vehicle systems. The vehicle engine mount system generally, consists of an engine (vibration source) and several mounts connected to the vehicle structure (Yan et al, 2009). Therefore, in order to resolve noise and vibration problems generated by vehicle engine, various types of engine mounts have been proposed (Deng and Zheng, 2011; Hosseini, 2010). An engine mounting system rubber components primary role is to attenuate the engine vibration which transmitting to body, improving NVH (Noise, Vibration and Harshness) performances of vehicles (Zhang et al, 2009).It should isolate the body structure from the engine forces and engine from chassis vibration due to the road and wheels irregularities.

Traditionally, most of the cars use passive engine mounting which is made of elastomer or rubber (Wijaya et al, 2009). A rubber mount can be modelled as a spring damper system as being shown in Fig. 1 (Hosseini, 2010). The main issue for conventional elastomeric mount is, it damping and stiffness can't be tuned (fix). Thus, the stiffness and damping properties of elastomer need to be chosen correctly in order to obtain the optimum vibration suppression (Cheli et al, 2011). Moreover, it can only isolate single frequency vibrations and effective only in limited range of excitation frequencies (Wijaya et al, 2009; Elahinia et al, 2013; De Silva, 2000).

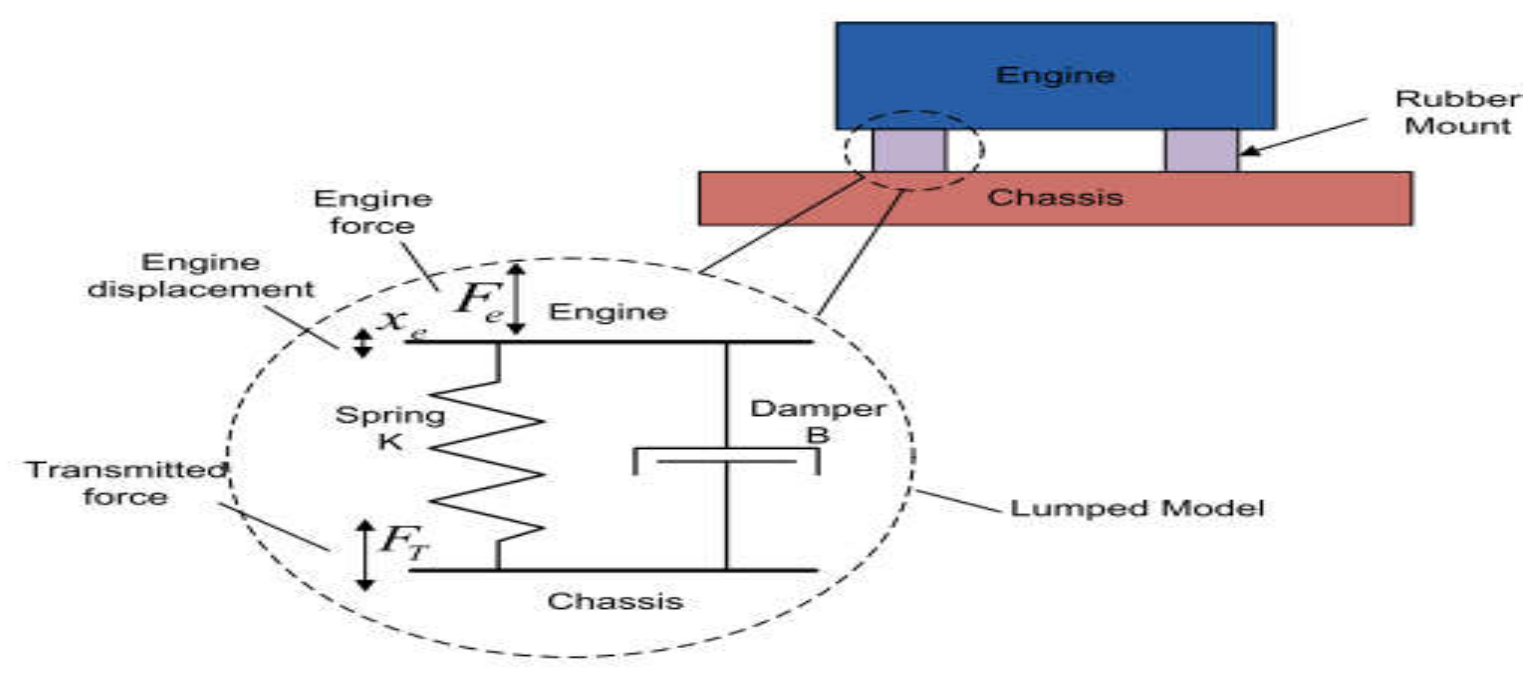

Fig.1.A lump model of rubber engine mount (Hosseini, 2010)

Hydraulic Engine Mounts (HEMs) are the next generation of engine mounts which can be classified into three types namely hydraulic mount with simple orifice, hydraulic mount with inertia track and hydraulic mount with inertia track and decoupler (Yu et al, 2011). Even 
though there are difference in terms of mechanism, but all of them can provide greater damping in low frequency range that have made them favourable in vehicle industry (Andren, 1993). However, there are still some drawbacks such as the parameters of the hydraulic mounts need to be tuned manually and it can only fulfil a specific system within a certain frequency range ( $\mathrm{Yu}$ et al, 2001). Another issues involve in fluid are aging or loss of fluid and contamination to the environment (Andren, 1993).

In order to improve the performance of passive and hydraulic engine mounts an active and semi active engine vibration control design has been implemented to the engine mount design. Main differences between those two control designs are located in the mechanism of the system to counteract the force being applied into the system. In active engine mounts, piezoelectric actuators or electromagnetic actuators are used to apply anti-vibration forces to the engine and chassis to cancel unwanted vibrations (Fakhari et al, 2015). Several researchers have already proven the effectiveness of active engine mount system by isolating the engine vibration using different controllers such as $\mathrm{H}_{2}$ controller (Olsson, 20060, $\mathrm{H}_{\infty}$ controller (Fakhari and Ohadi, 2013), Fuzzy controller (Liang et al, 2009) and Neural network controller (Darsivan, 2009). Even though active engine mount has been proven to be effective to reduce the vibration but their high cost, complexity, weight and energy consuming have made their application limited (Wijaya et al, 2009). Among these factors, cost and complexity are the most crucial issues as far as automotive industries are concerned.

In contrast, semi active engine mount can only dissipate energy through varying the corresponding parameters of the system such as spring stiffness or coefficient of viscous damping (Yuyou, 2004). A compressive review about the semi active engine mount using magnetorheological and electrorheological fluid has been illustrated by Elahinia et al in their article (Elahinia et al, 2013). An engine mount as a vibration isolator has been reviewed in this paper. Basically, a passive hydraulic vibration isolator has been converted into a semi active device.

Several mechanisms have been designed and invented by different researchers in order to achieve better vibration behavior by employing smart fluids (Fakhari et al, 2015).

Currently, semi-active mounts rely on changes in geometry of the flow paths or on changes in 
properties of the working fluid (Feyzi et al, 2011). It is more desirable to change the mount response by changing the working fluid (MRF) characteristics rather than altering the geometry of the mounts. It is due to the fact that changes in geometry of the flow paths in real time require rather complex actuation mechanisms to be incorporated in the mount. However, it has been highlighted by several researchers that as a fluid filled mounting components, MRF still open to some drawbacks such as shortcoming of particle sedimentation because of density mismatch between particles and the carrier fluid (Stefan and Kajaste, 2011), achievable yield stress, the stability and durability of the fluid (Acocella et al, 2010), settling due to differences in specific gravities and wear of the magnetic particles (Jerzy, 2012).

From all the reviewed paper, there is a need for researcher to investigate further the mechanism, design or material that can be deployed in the engine mount system or fabrication design in order to obtain the best vibration isolation performance. Even though current engine mounting system has been for a long time and proven to be successful to isolate the driver and passenger from the noise and vibration, there is a need to improve the performance of engine mount system for the following two reasons: one is the requirement of vibration and noise isolation for passenger cars, the other is that modern car design has a trend for lighter car body, higher speed and larger power-intensive engine (Yu et al, 2001). Thus, this paper proposes a modelling for three degree of freedom of engine mounting system as a first step to investigate the performance of current passive engine rubber mounting system.

This paper is organized as follows: The introduction and previous works on engine mounting system are explained in the first section. The second section focuses on the mathematical equations of the three degree of freedom engine mounting system. The third section presents the experimental setup and the necessary instrumentation for collecting the appropriate signal from the system. The experimental results will be compared with the simulation result of the engine mounting system via MATLAB environment in the fourth section. The last section presents the conclusions.

\section{RESULTS AND DISCUSSION}

The govern equations of three mount engine mounting system has been simulated in the 
MATLAB Simulink. The input for the simulation was a sine wave that replicated the harmonic force from the engine excitation. The effect of internal forces due to bearing, mounting and friction has also been considered as part of the input by adding the uncertainties force from the center of the engine to the harmonic sine wave input. Simulation study was performed for a period of $7 \mathrm{~s}$ to simulate the engine excitation response to the engine mount (passive rubber).The model is simulated using Ode 4 (RungeKutta) with fixed step size of 0.01.Comparison between simulation model and experimentation data at three engine mounting location (Rear Right, Rear Left and Front) for three different revolution per minute of engine excitation (1180, 2145 and 2540 RPM) has been performed for the purpose of model validation. The schematic diagram of the validation procedures can be seen in Fig. 2 .

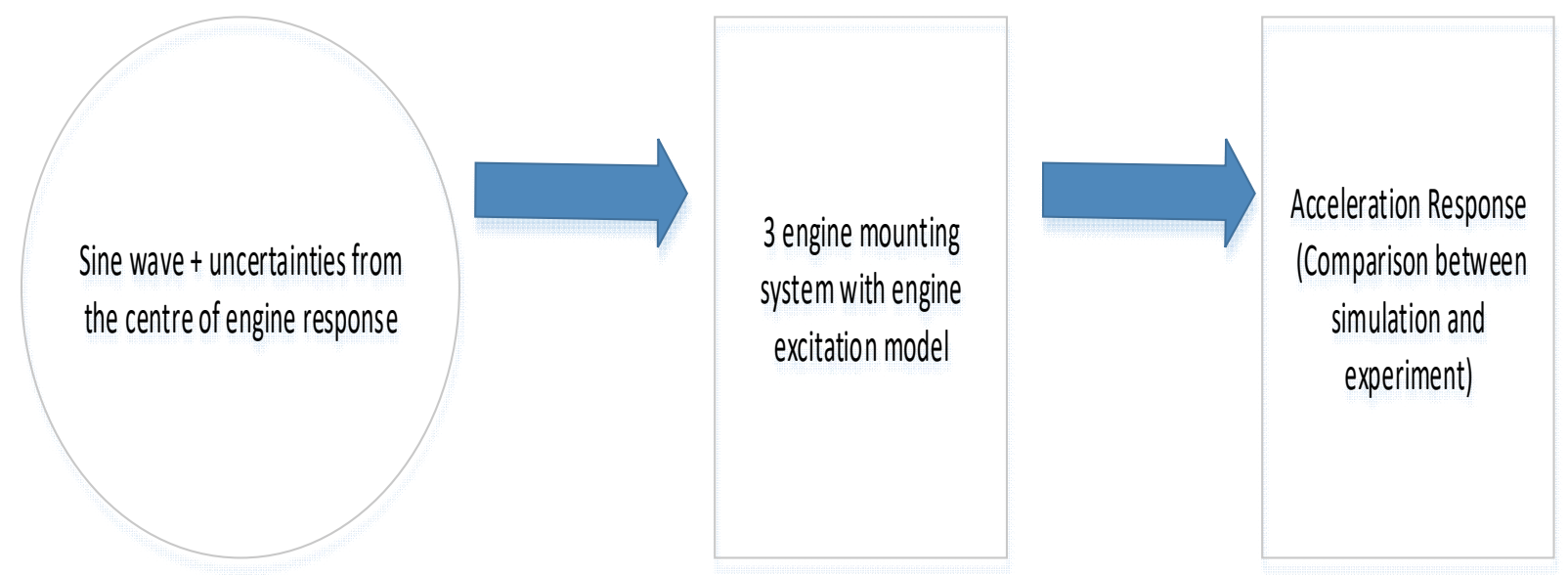

Fig.2. Schematic diagram for validation of three engine mount model

The simulated model has been verified with the data from real experimental result by Root Mean Square (RMS) value at three different engine mount location (Rear Right, Rear Left and Front). RMS value of the acceleration was chosen since the outcome from the accelerometer is a sinusoidal wave due to the reciprocating of the crankshaft in the engine. Thus, a RMS value is a good indicator to represent variable amplitude values of the engine mount acceleration since it is an effective average value of the acceleration. Percentage different between experimental and simulation value in terms of RMS value at three different engine mount location has been tabulated in Table 1 . 
Table 1. Percentage difference between experimental and simulation value in terms of RMS value at three different engine mount location (Exp=Experiment, $\operatorname{Sim}=$ Simulation $)$

\begin{tabular}{cccc}
\hline & 1180 RPM & 2145 RPM & 2540 RPM \\
\hline ZSRL & $0.0666($ Exp) vs 0.0634 & $0.1402($ Exp) vs 0.1348 & $0.1983($ Exp) vs 0.1907 \\
& $($ Sim $)>>5 \%$ & $($ Sim $)>>4 \%$ & $($ Sim $)>>3.9 \%$ \\
ZSRR & $0.1469($ Exp) vs 0.1400 & $0.2818($ Exp)vs 0.2684 & $0.2282($ Exp) vs 0.2174 \\
& $($ Sim $)>>4.9 \%$ & $($ Sim $)>>4.9 \%$ & $($ Sim $)>>4.9 \%$ \\
ZSF & $0.0385($ Exp) vs 0.0370 & $0.0869($ Exp) vs 0.0831 & $0.1182($ Exp) vs 0.1132 \\
& $($ Sim $)>>5 \%$ & $($ Sim $)>>4.5 \%$ & $($ Sim $)>>4.4 \%$ \\
\hline
\end{tabular}

In this table, ZSRL representing the RMS acceleration value at rear left, ZSRR representing the RMS acceleration value at rear right and ZSF representing RMS acceleration value at front engine mount. The comparison between the experiment and simulation in terms of acceleration response and also vertical acceleration error can be seen in all 9 graphs as being shown below.

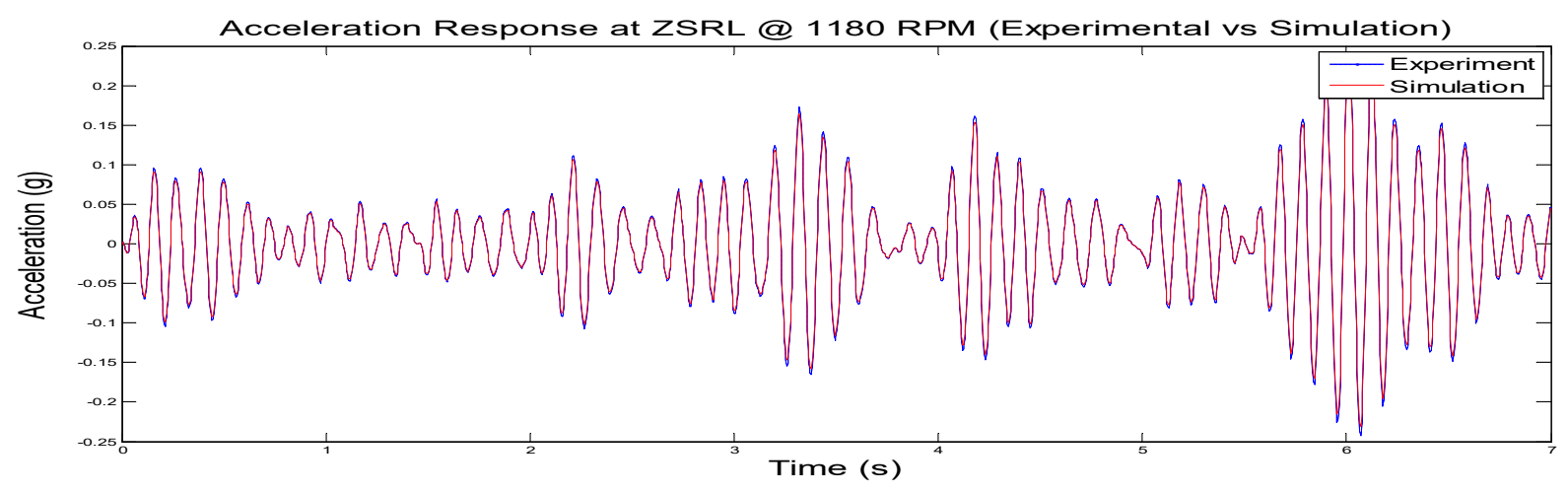

(a)

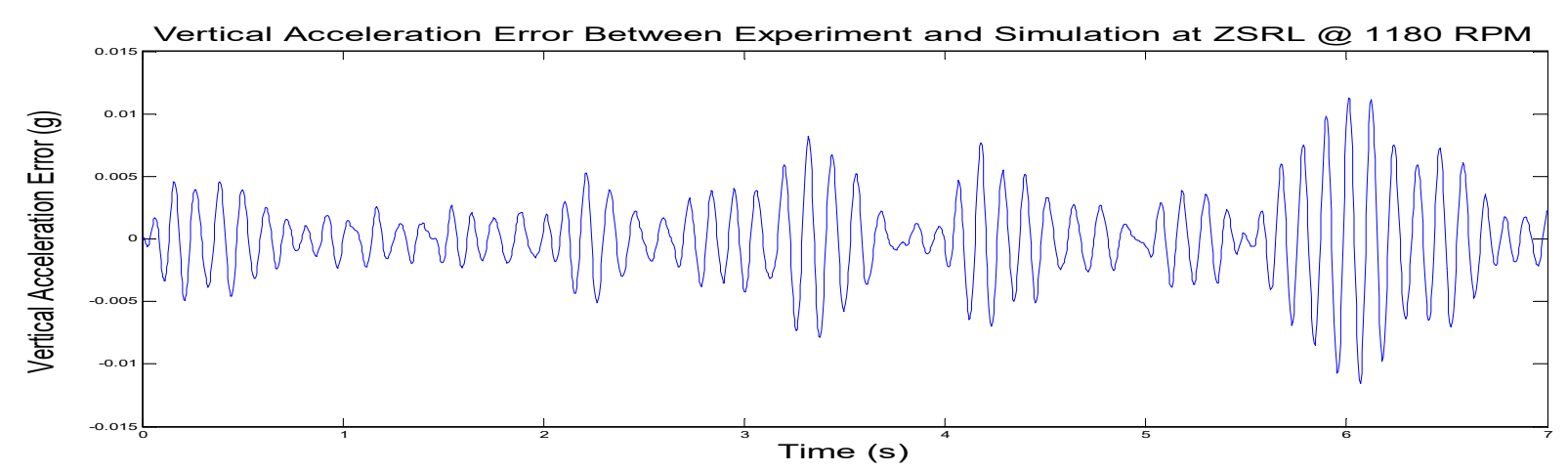

(b)

Fig.3. a) Acceleration response at ZSRL @1180 RPM b) vertical acceleration error at ZSRL 


\section{(a) 1180 RPM}

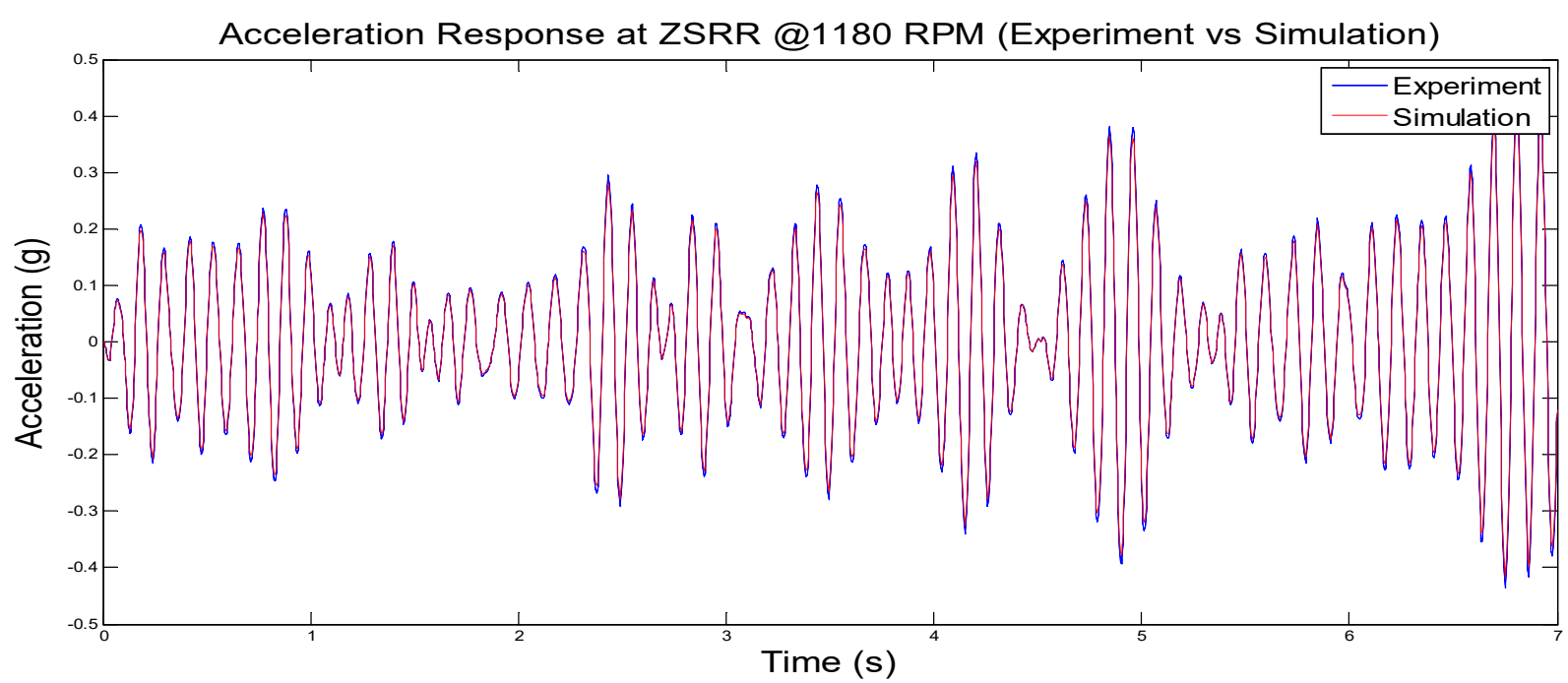

(a)

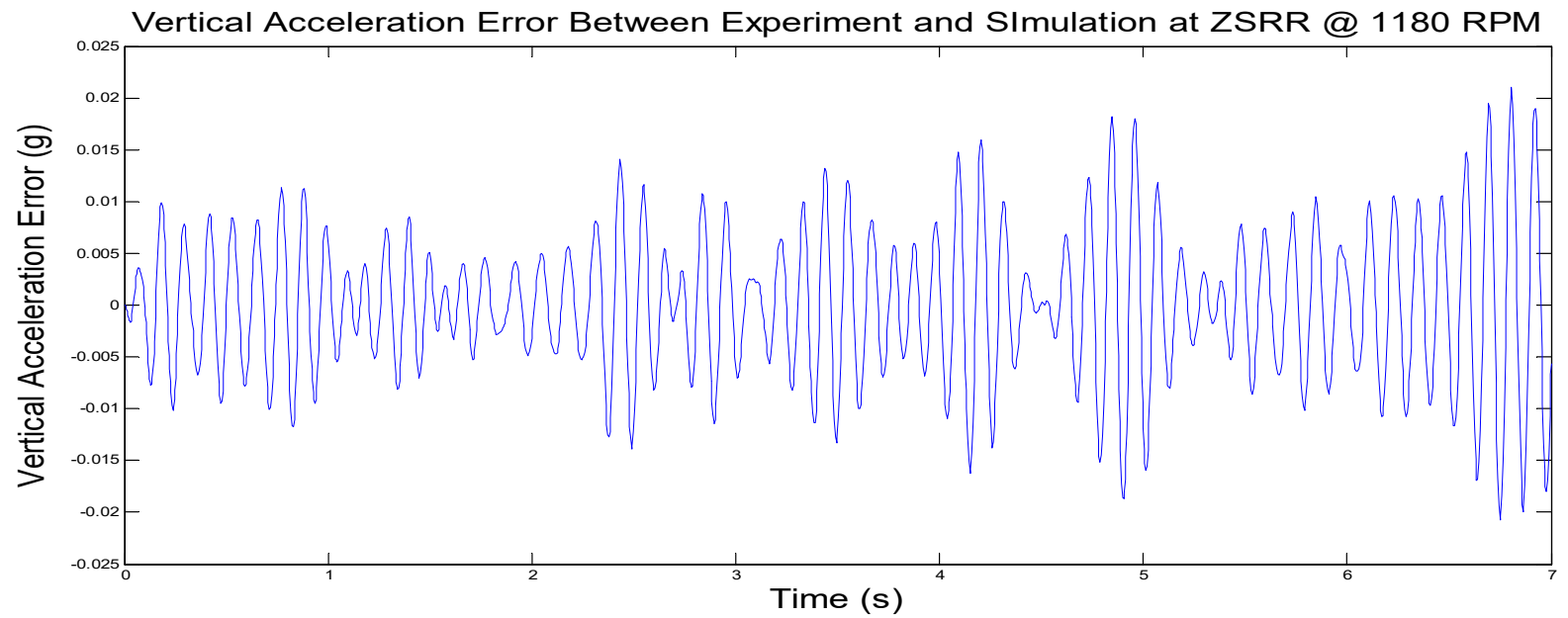

(b)

Fig.4. a) Acceleration response at ZSRR @ 1180 RPM b) vertical acceleration error at ZSRR @ 1180 RPM 


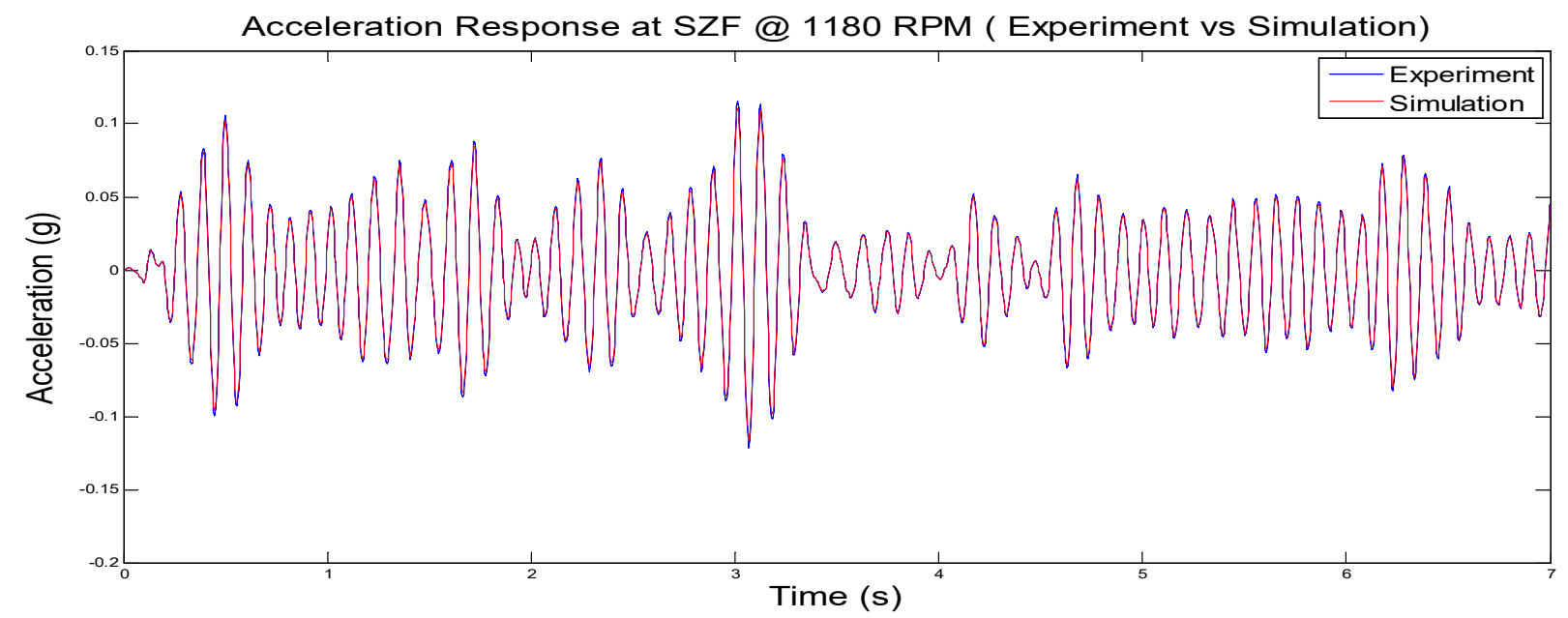

(a)

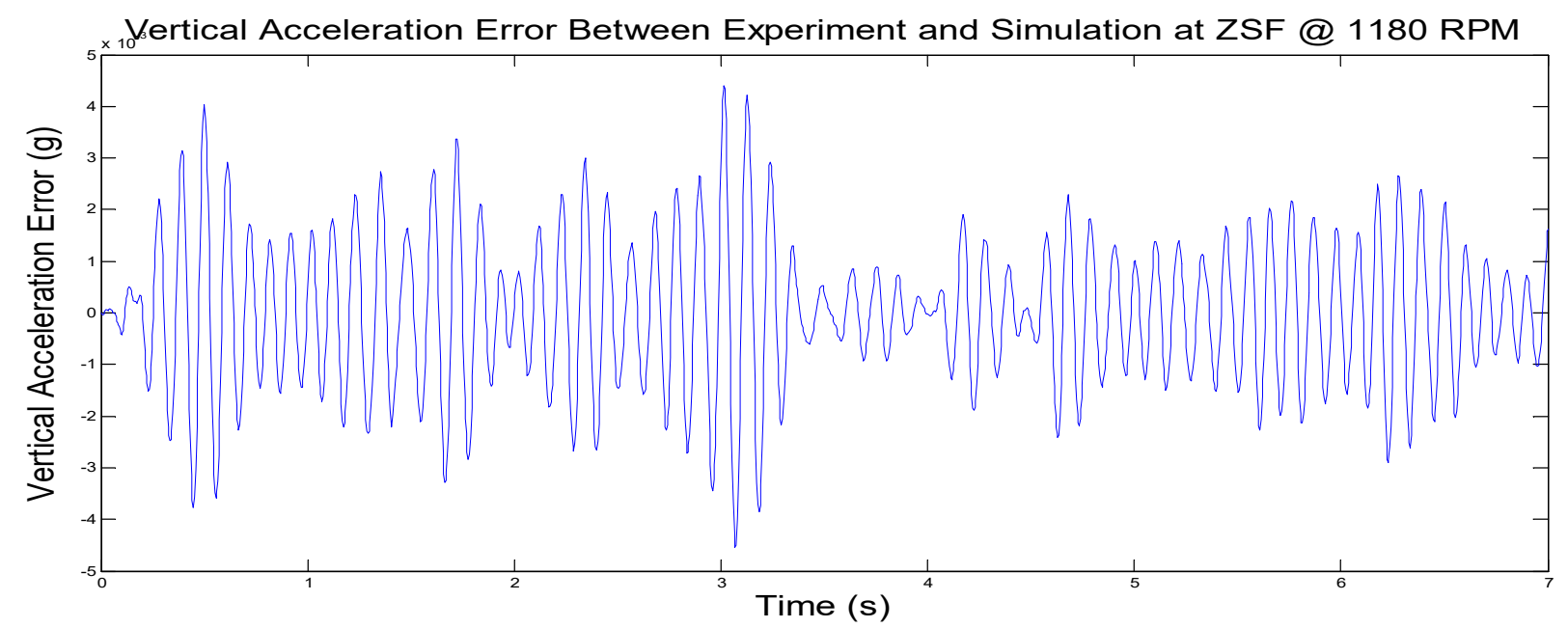

(b)

Fig.5. a) Acceleration response at ZSF @ 1180 RPMb) vertical acceleration error at ZSF @

\section{RPM}

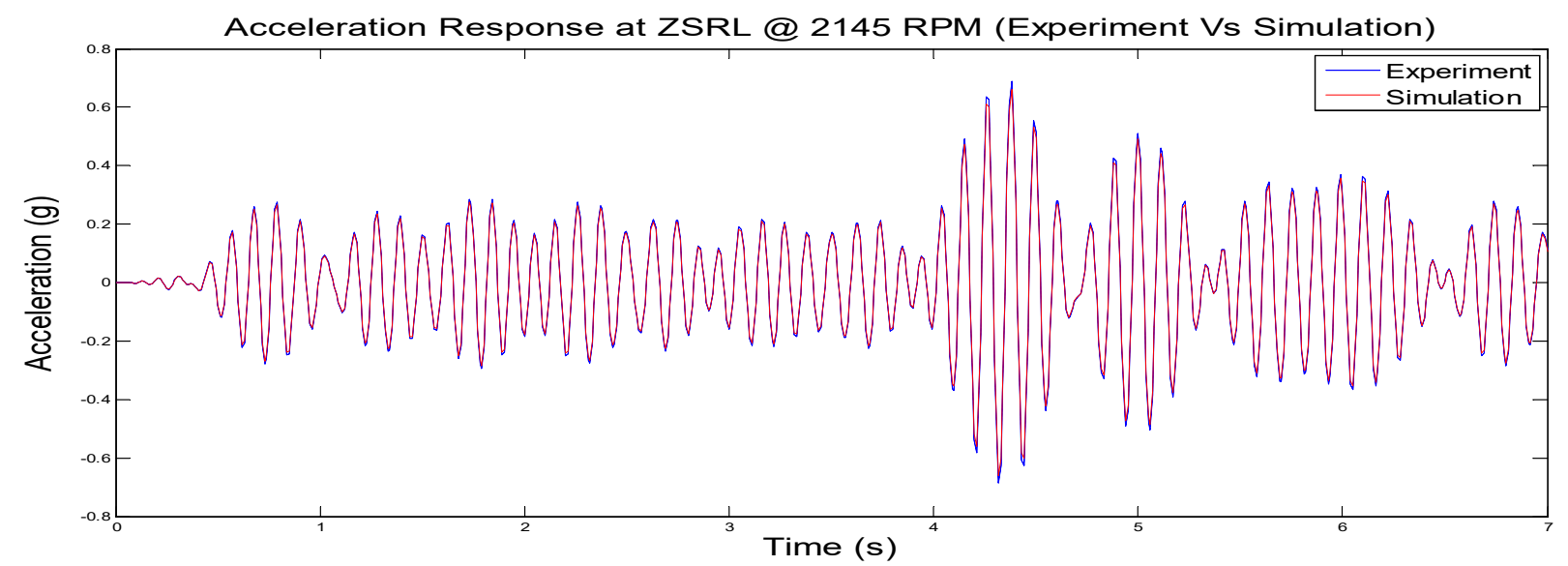

(a) 


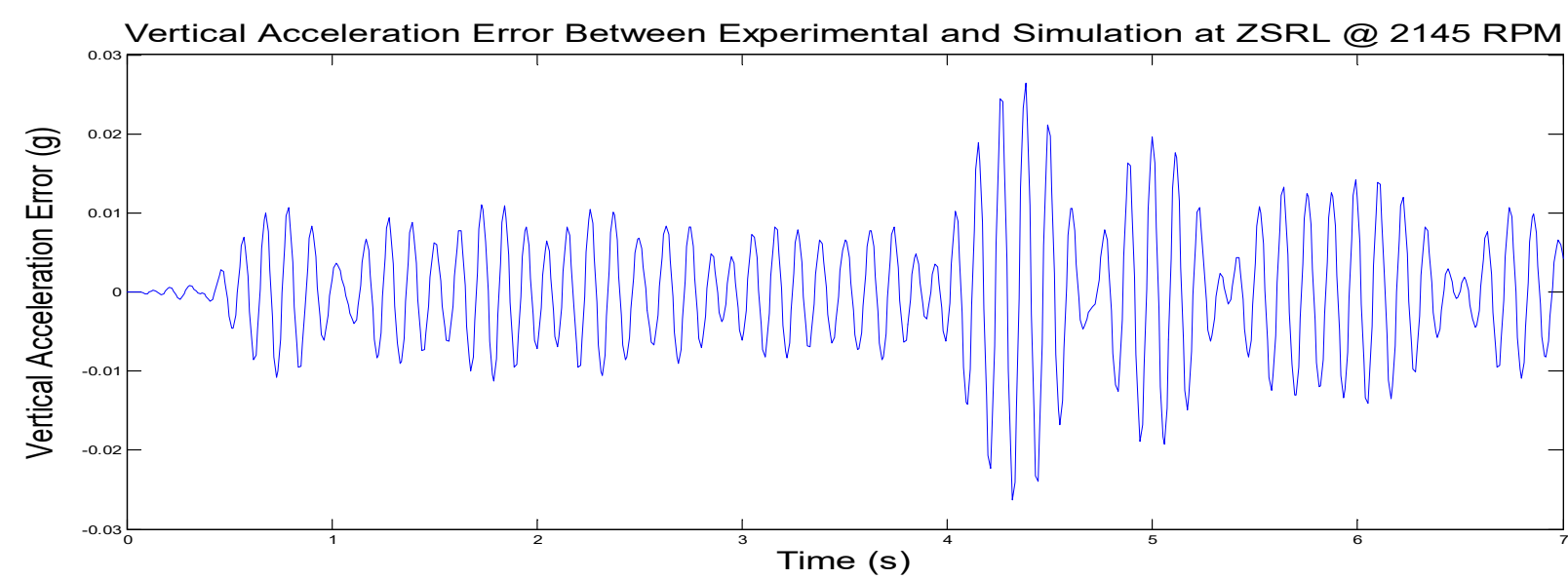

(b)

Fig.6. a) Acceleration response at ZSRL @ 2145 RPM b) vertical acceleration error at ZSRL

$$
\text { (a) } 2145 \text { RPM }
$$

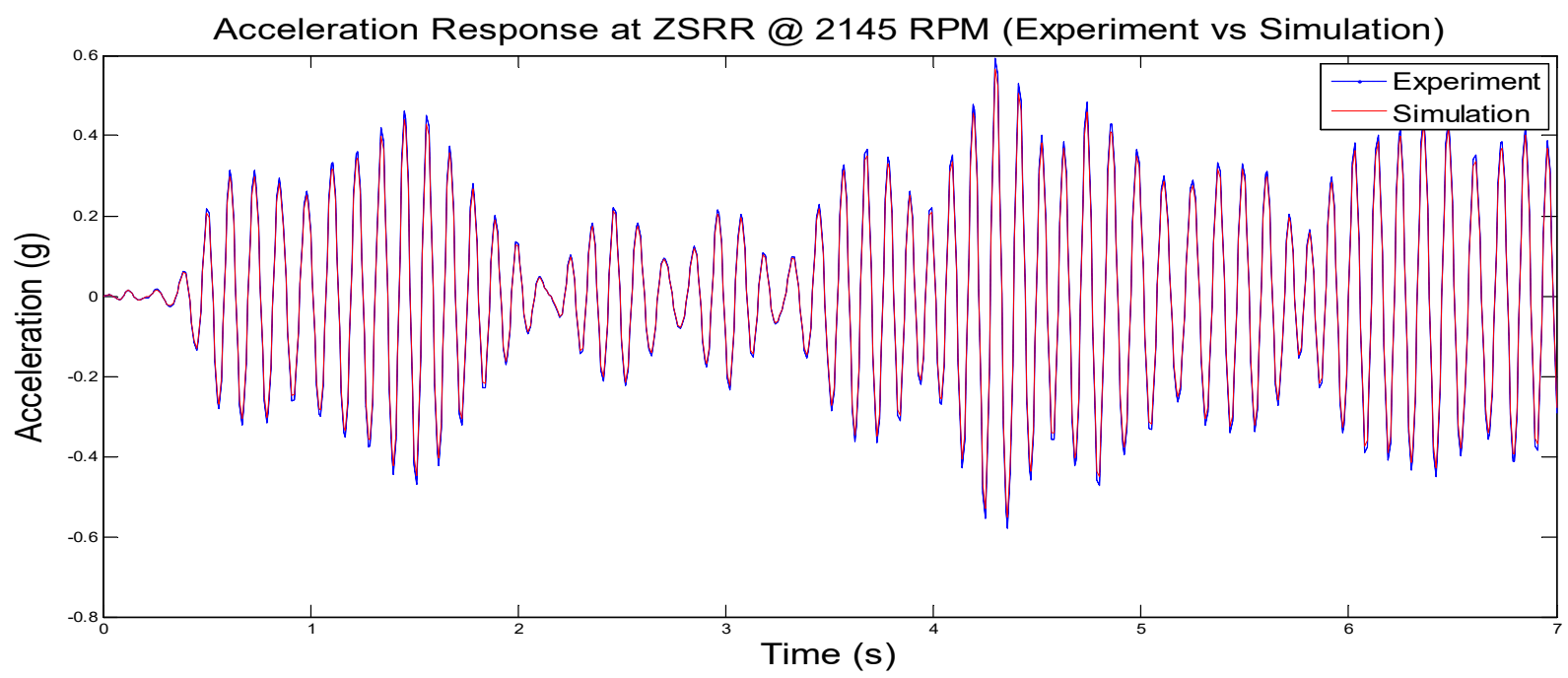

(a)

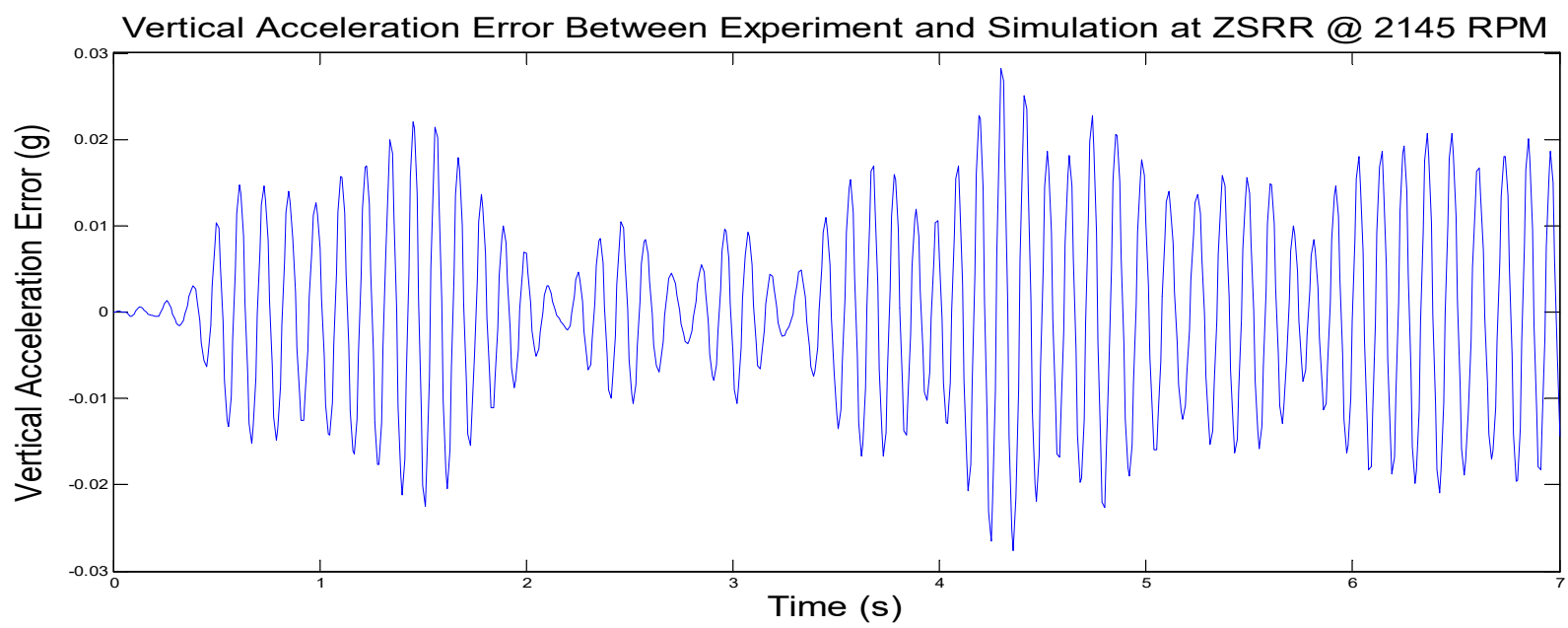

(b) 
Fig.7. a) Acceleration response at ZSRR @ 2145 RPM b) vertical acceleration error at ZSRR (a) 2145 RPM

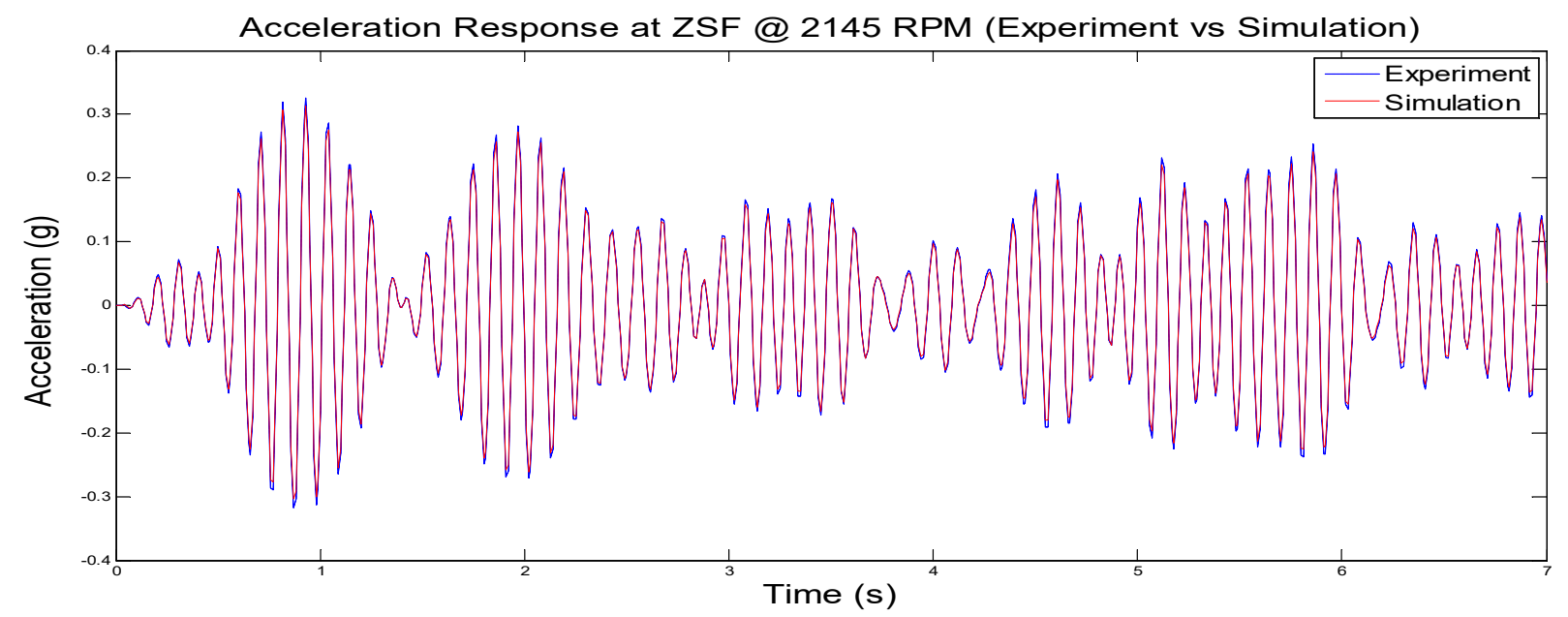

(a)

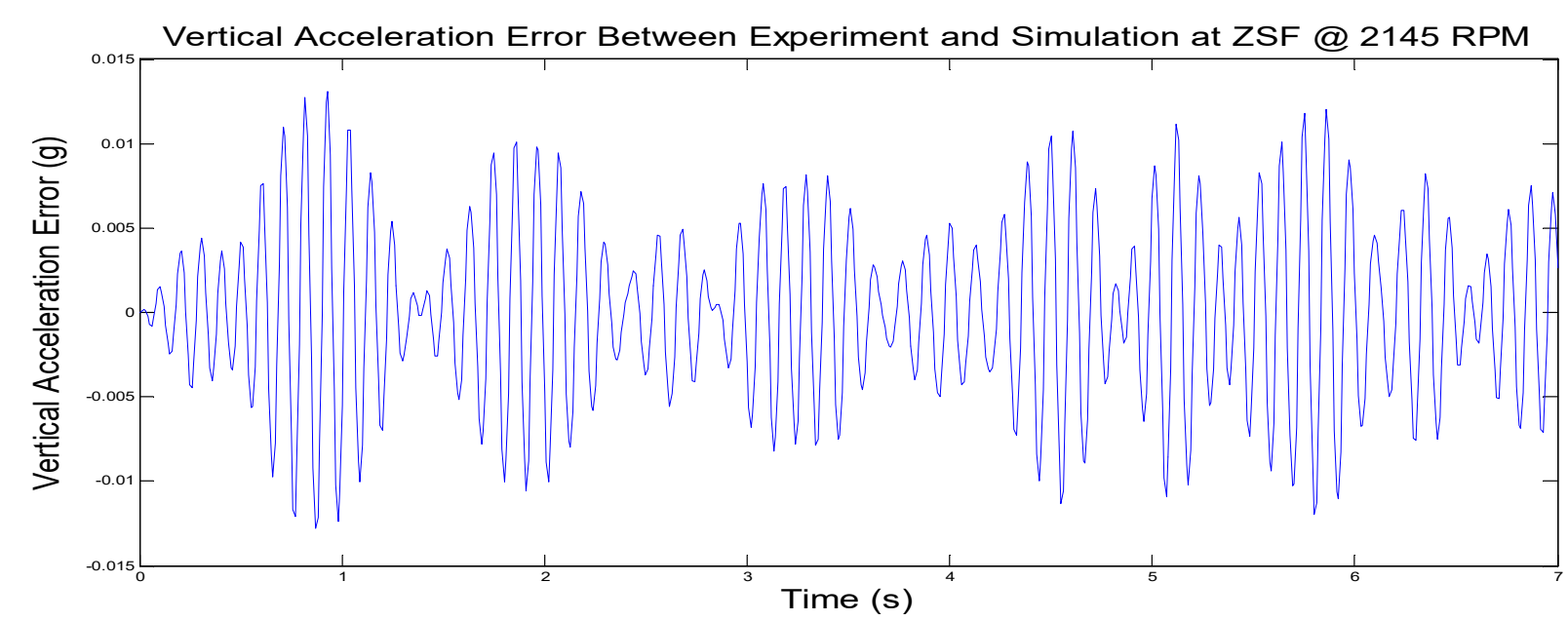

(b)

Fig.8.a)Acceleration response at ZSF@2145 RPMb) vertical acceleration error at ZSF @ 2145 RPM

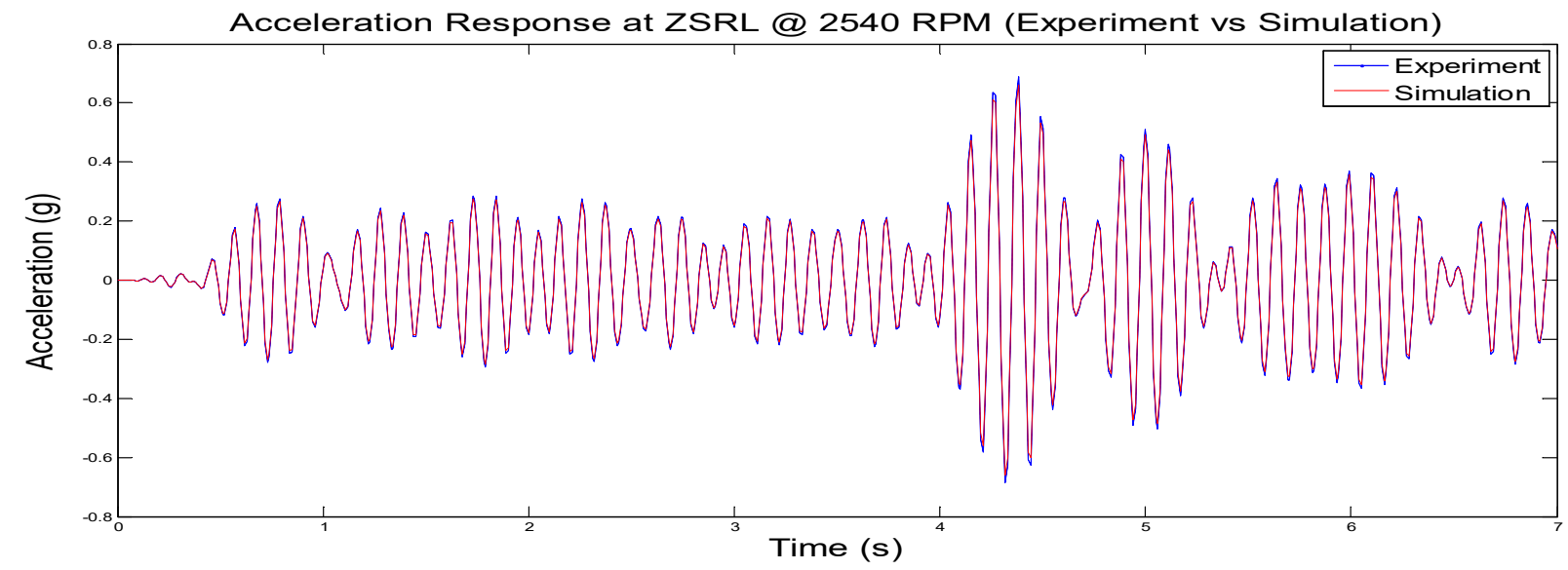


(a)

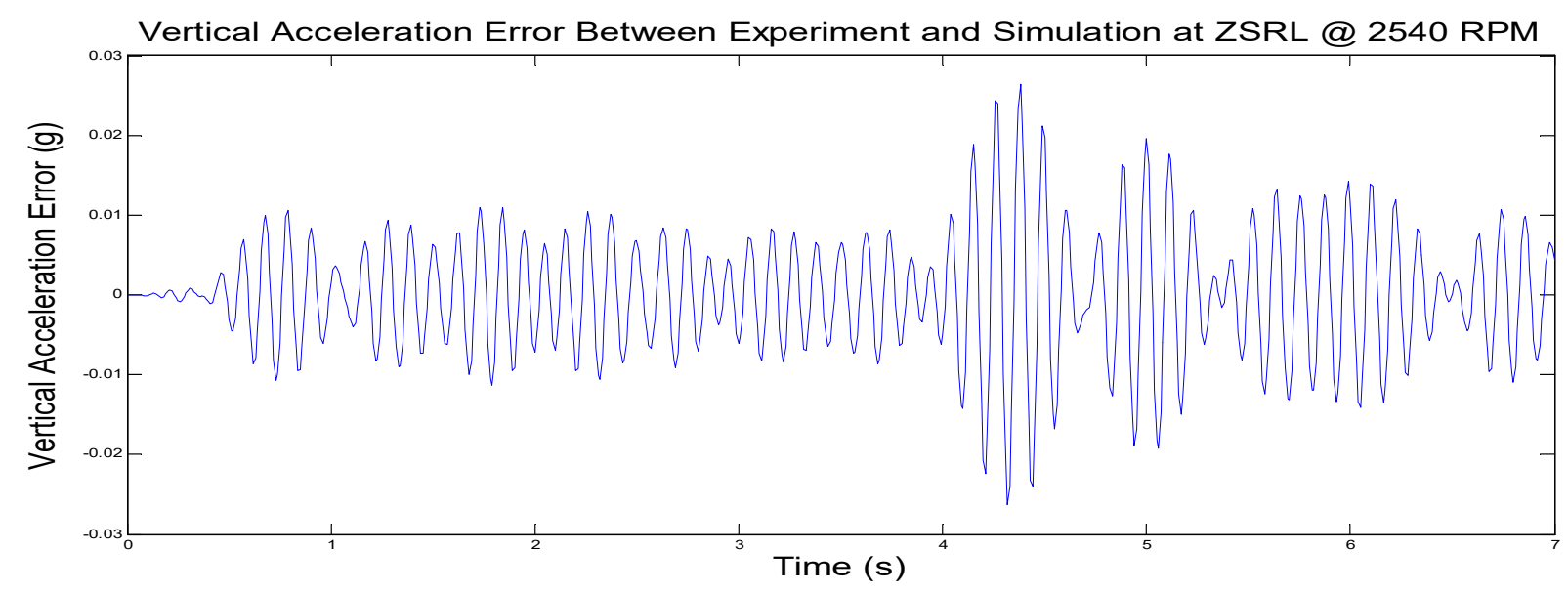

(b)

Fig.9. a) Acceleration response at ZSRL @ 2540 RPM b) vertical acceleration error at ZSRL (a) 2540 RPM

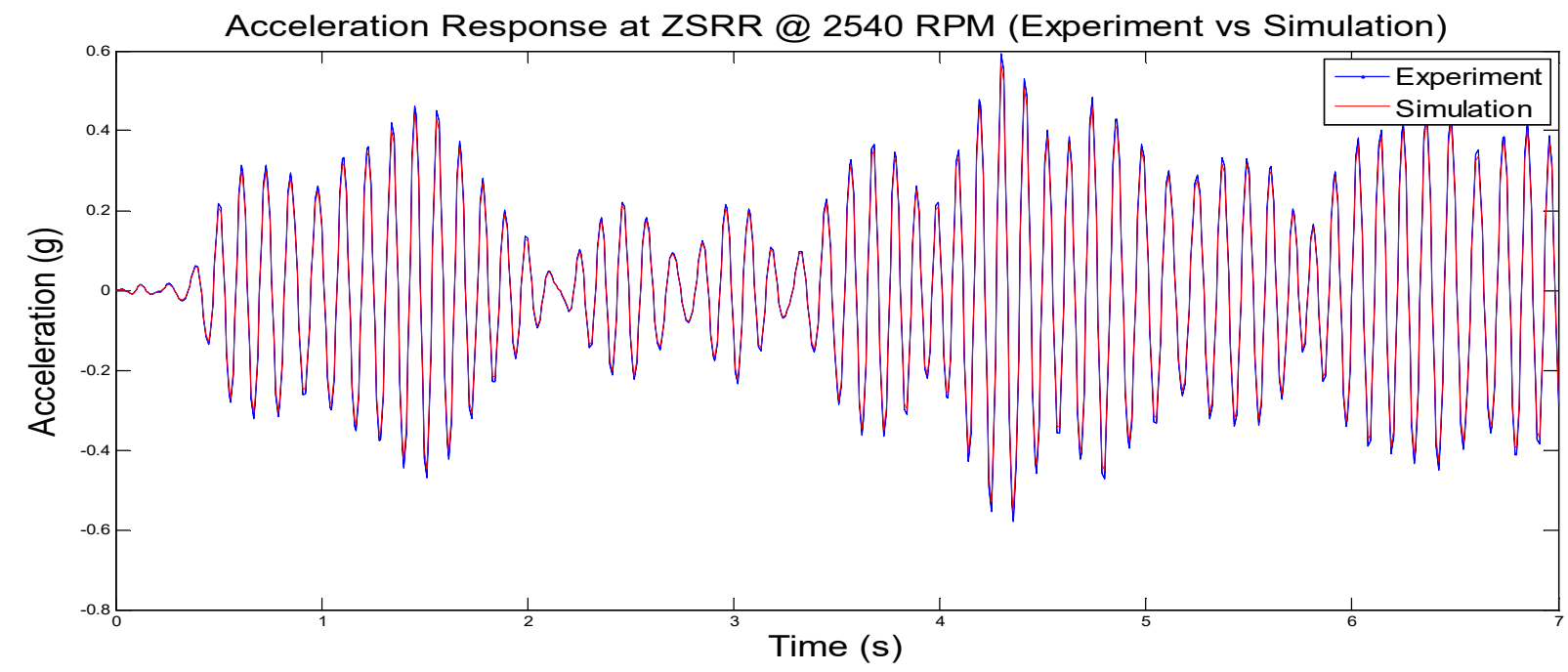

(a)

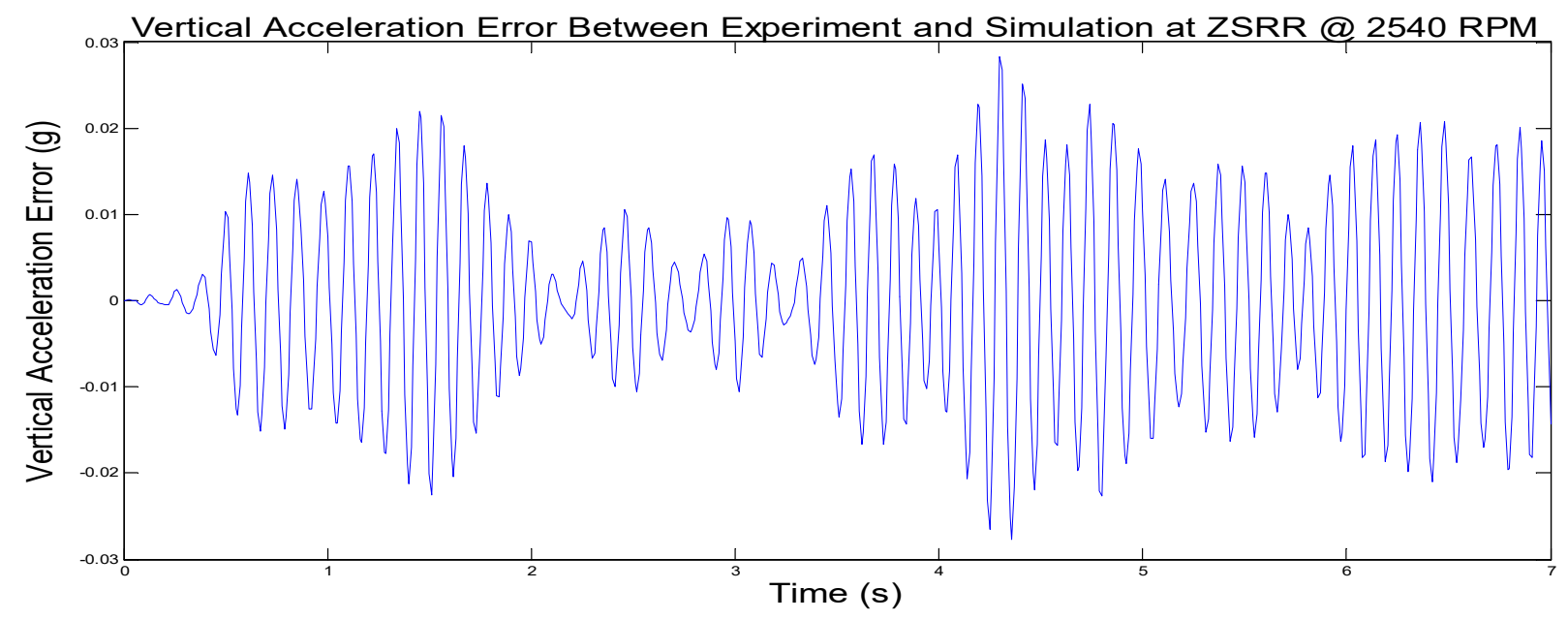


(b)

Fig.10. a) Acceleration response at ZSRR@2540 RPM b) vertical acceleration error at ZSRR@2540RPM

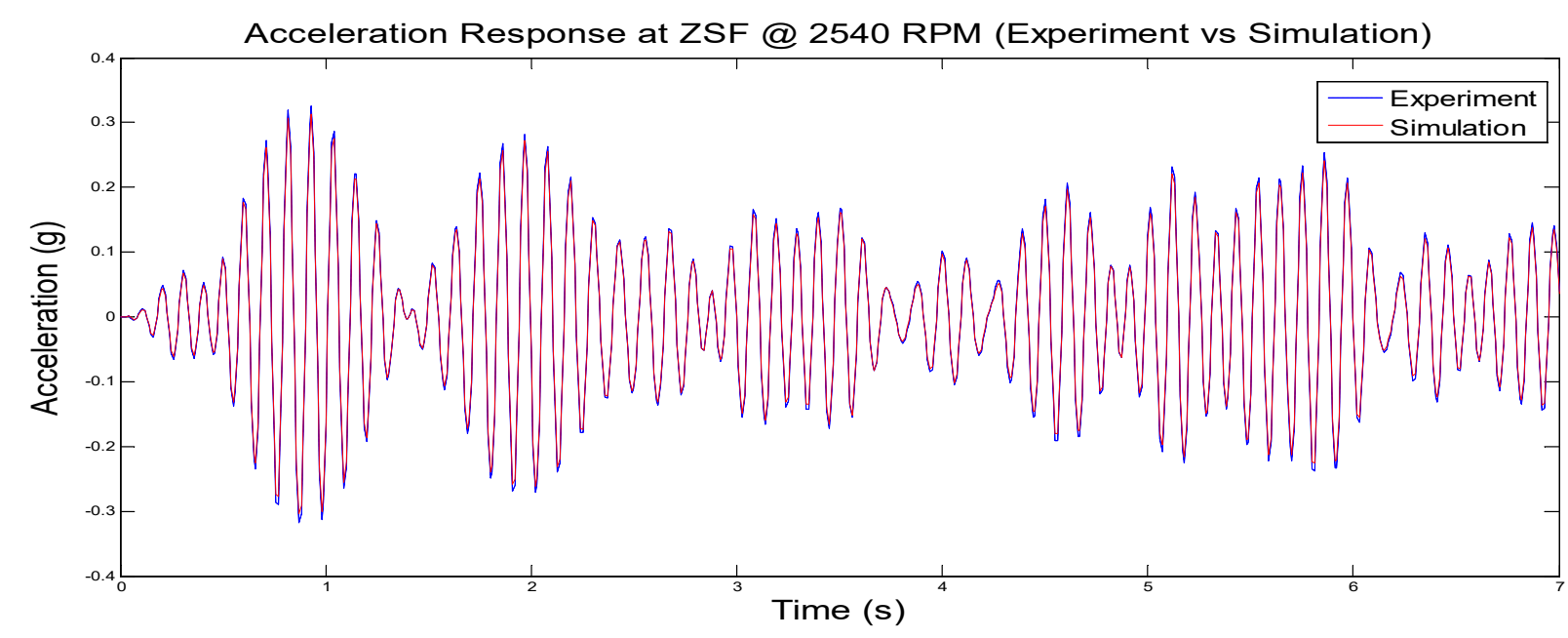

(a)

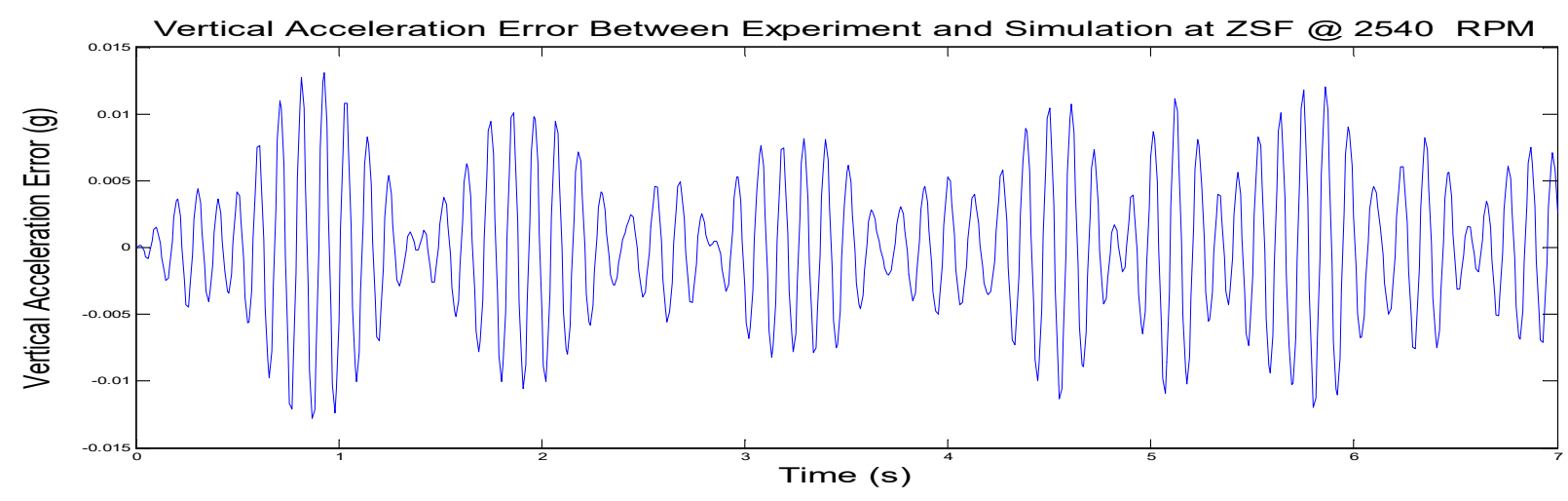

(b)

Fig.11. a) Acceleration response at ZSF @ 2540 RPMb) vertical acceleration error at ZSF @ 2540 RPM

In this study, the response from the real engine mount system from the test bench is used as a benchmark to compare the acceleration response of the simulation model. Fig. 3 to 11 show the acceleration response of the simulated model as compared to the experimental result. As being indicated in Table 1, the RMS acceleration values between the simulated and experimental has only a small difference. The response from the simulation shows that the RMS acceleration is varying between 3.9 to 5 percent at the three engine mount locations. The same results were obtained for different engine excitation revolution. Another important result for the validation purposes of the simulated model was a vertical acceleration error. This error 
shows the differences between the vertical displacement obtained from the experiment and simulation. The vertical acceleration error shows a small difference. For example, in Fig. 4 the error was around 0 to $0.01 \mathrm{~g}$. The highest error can be seen in Fig. 9, where the error value was roughly indicated around $0.03 \mathrm{~g}$.

It has been shown by the plotted graphs in Fig. 3 to 10 that the simulated model can resemble the experimental results obtained with a small error in terms of rms as well as vertical acceleration error. The differences can be traced back by looking at the possible engine excitation sources in the system. Engine disturbances in real experimental which is coming from unbalanced force and torques inside the engine are among the possibilities of reason for the result (Foumani et al, 2003). Precisely, the cyclic motion of crankshaft is the main reason of the phenomenon which will result in high-frequency, small-amplitude vibrations transmitting to the chassis (Fakhari et al, 2015). Apart from that, an experimental error also can be happened due to the placement of the sensors at the engine mount was affected by the engine vibration which make it tilted a little bit during experiment. Thus, the small differences in the result should be acceptable and the proposed model shows it capabilities to capture the real engine mount system response.

\section{EXPERIMENTAL}

The equation based on three degree of freedom has been derived where the engine has been assumed to move in vertical, pitch and roll direction only. The engine mount has been modelled as spring and damper in parallel as shown in the schematic diagram in Fig. 11.In order to make the model for easier for derivation it was simplified into Free Body Diagram (FBD) as shown in Fig. 12. Using FBD the dynamics behaviour of the engine mount system in terms of pitch, roll and vertical motions are derived mathematically using equations of motions from Newton's second law as follows. 


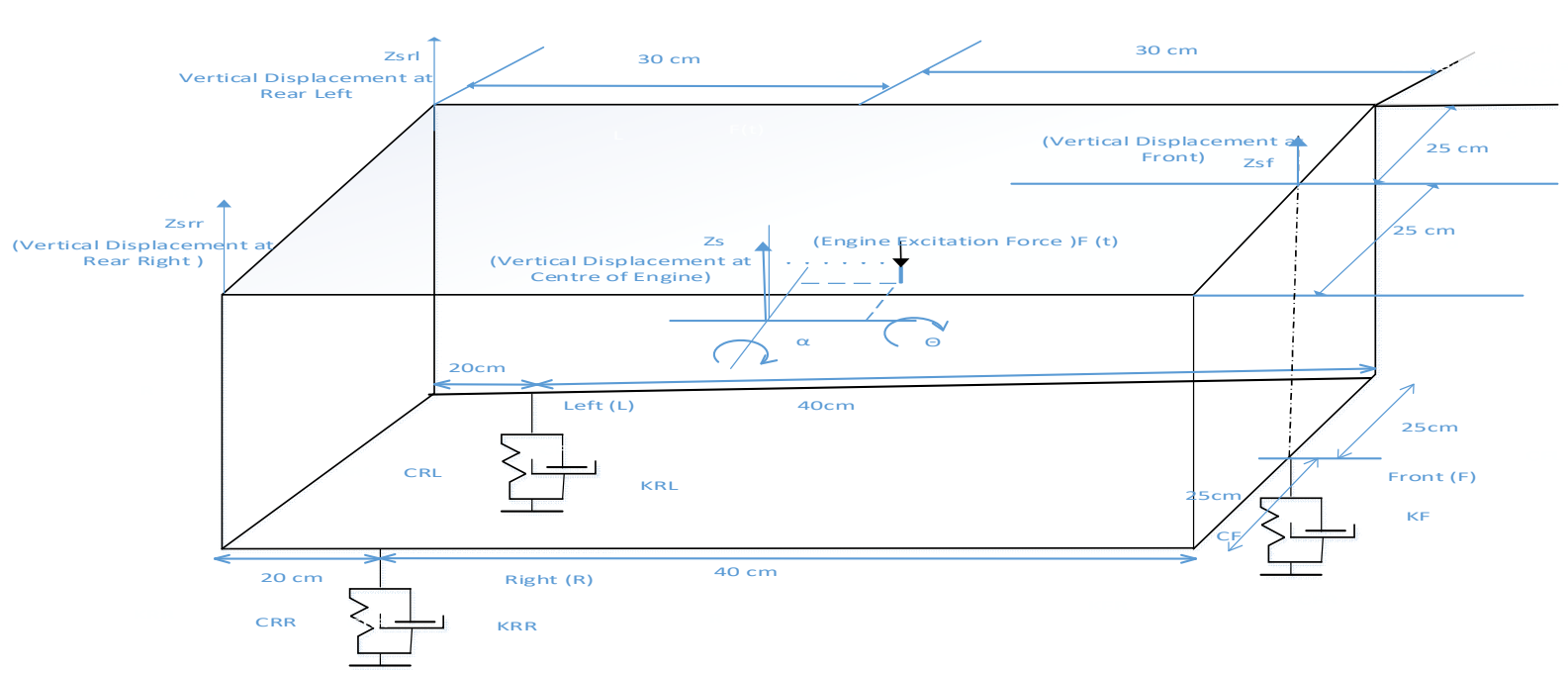

Fig.12. Schematic diagram of three engine mount system

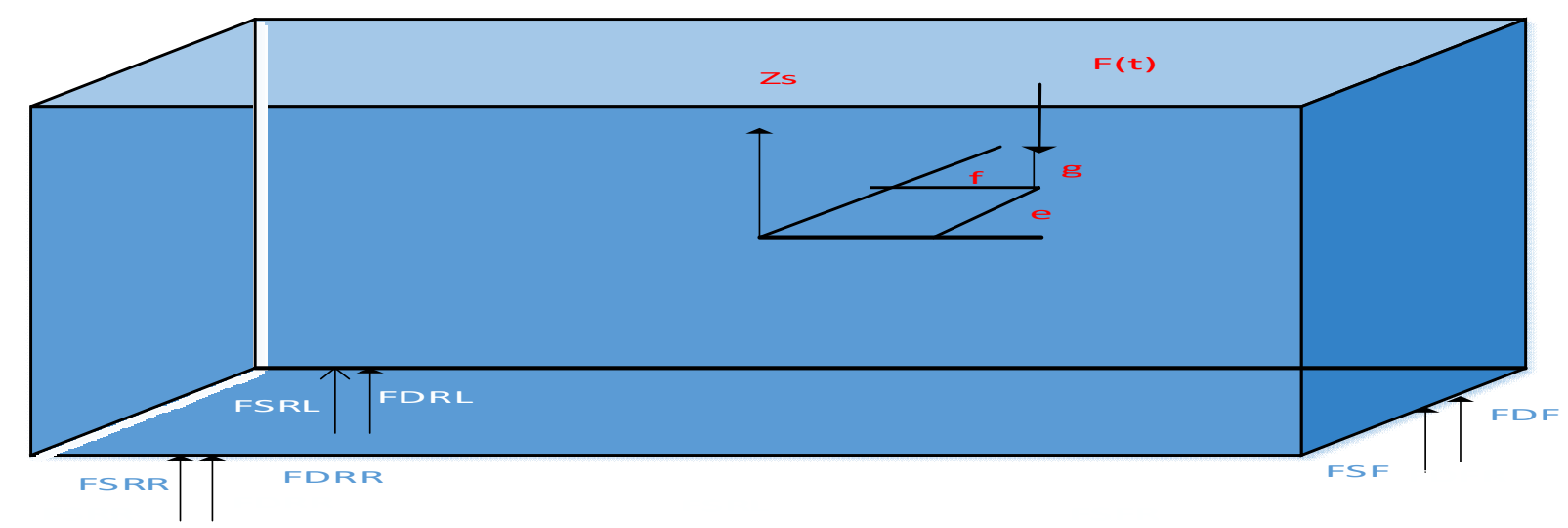

Fig.13. Free body diagram of three degree of engine mount system

The three main equations that govern the system are:

1. $\sum F_{v}=m \ddot{Z}_{s}$

$F_{s r r}+F_{d r r}+F_{s r l}+F_{d r l}+F_{s f}+F_{d f}-F(t)=m \ddot{Z}_{s}$

2. $\sum M_{p}=I_{p} \ddot{\alpha}$

$$
\begin{gathered}
F_{s r r}\left(\frac{b}{2}\right)+F_{d r r}\left(\frac{b}{2}\right)+F_{s r l}\left(\frac{b}{2}\right)+F_{d r l}\left(\frac{b}{2}\right)-F_{s f}\left(\frac{b}{2}\right)-F_{d f}\left(\frac{b}{2}\right)+F(t) e \\
=I_{p} \ddot{\alpha}
\end{gathered}
$$

3. $\sum M_{R}=I_{R} \ddot{\theta}$

$F_{s r r}\left(\frac{a}{2}\right)+F_{d r r}\left(\frac{a}{2}\right)-F_{s r l}\left(\frac{a}{2}\right)-F_{d r l}\left(\frac{a}{2}\right)+F(t) f=I_{R} \ddot{\theta}$

The force of spring and damper at the three engine mount location can also be derived using Newton's Second Law as follows:

$F_{\text {srr }}=K_{\text {srr }} Z_{\text {srr }}$ 


$$
F_{d r r}=C_{s r r} \dot{Z}_{s r r}(5) F_{s r l}=K_{s r l} Z_{s r l}(6) F_{d r l}=C_{d r l} \dot{Z}_{s r l}(7) F_{s f}=K_{s f} Z_{s f}(8)
$$

$F_{d f}=C_{d f} \dot{Z}_{s f}$

where $F_{v}=$ force in vertical direction, $m=$ mass of the engine, $\ddot{Z}_{s}=$ acceleration in vertical direction, $F_{s r r}=$ spring force at rear right, $F_{d r r}=$ damper force at rear right, $F_{s r l}=$ spring force at rear left, $F_{d r l}=$ damper force at rear left, $F_{s f}=$ spring force at front,$F_{d f}=$ damper force at front, $M_{p}=$ moment in pitch direction, $I_{p}=$ moment of inertia in pitch direction, $\ddot{\alpha}=$ pitch acceleration, $b=$ width of engine, $F(t)=$ excitation force from engine, $e=$ distance from the centre of gravity to the force of engine excitation in $\mathrm{x}$ direction, $M_{R}=$ moment in roll direction, $I_{R}=$ moment of inertia in roll direction, $\ddot{\theta}=$ roll acceleration, $a=$ length of engine, $f=$ distance from the centre of gravity to the force of engine excitation in $\mathrm{y}$ direction, $K_{s r r}=$ stiffness value at rear right, $Z_{s r r}=$ displacement at rear right, $C_{d r r}=$ damping value at rear right, $\dot{Z}_{s r r}=$ velocity value at rear right, $K_{s r l}=$ stiffness value at rear left, $Z_{s r l}=$ displacement at rear left, $C_{d r l}=$ damping value at rear left, $\dot{Z}_{s r l}=$ velocity value at rear left, $K_{s f}=$ stiffness value at front, $C_{d f}=$ damping value at front and $\dot{Z}_{s f}=$ velocity value at front.

Three conditions have been considered in the derivation where the displacement and velocity at the engine mount will be affected due to the conditions.

The three conditions can be illustrated as follows:

1. Without pitch and roll

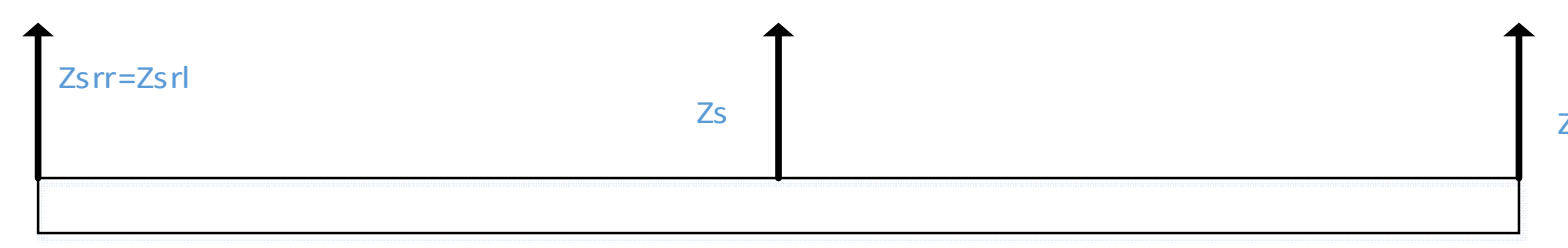

$Z s=Z s r r=Z s r l=Z s f$

Fig.12. Free Body Diagram (FBD) without pitch and roll

2. With pitch without roll 


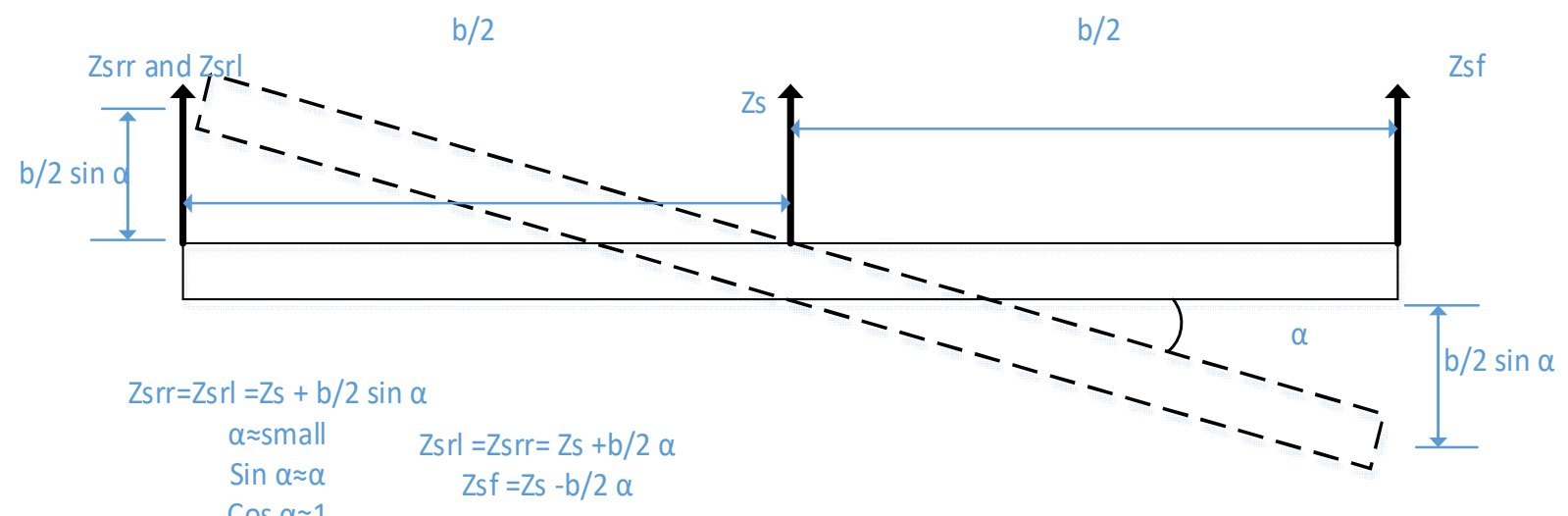

Fig.13. Free Body Diagram (FBD) with pitch without roll

3. With roll without pitch

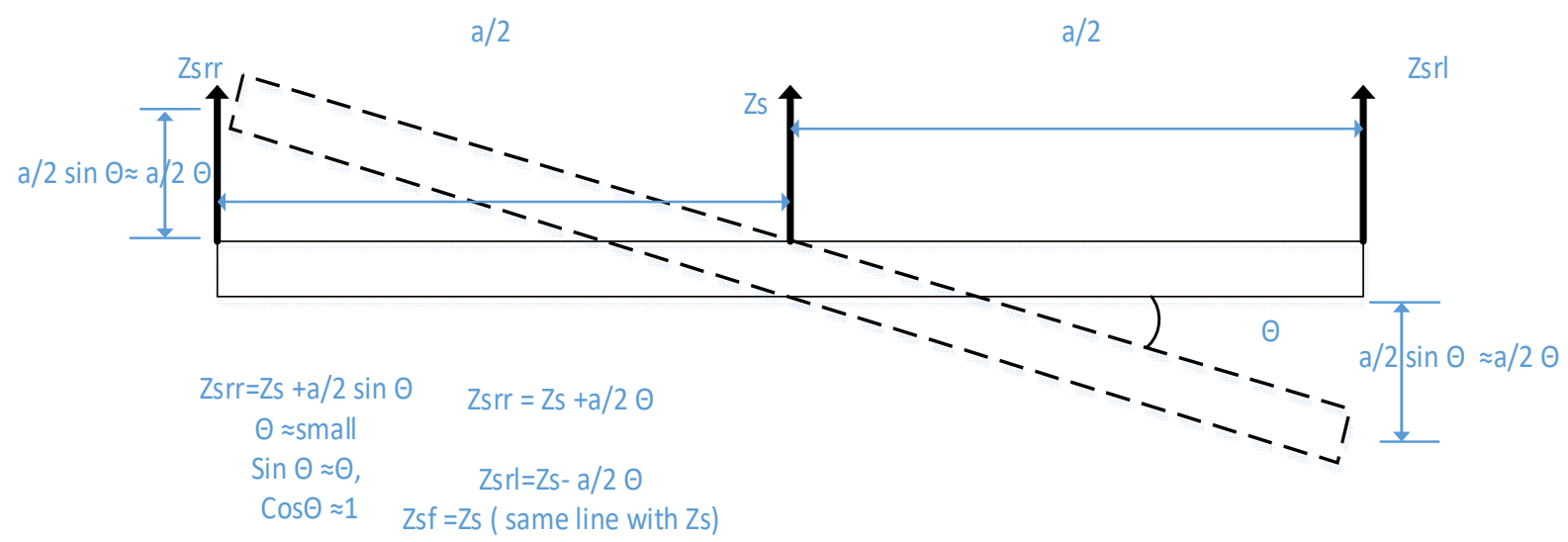

Fig.14.Free Body Diagram (FBD) with roll without pitch

From those three conditions the final equations which combine all three conditions can be derived as follows:

$\dot{Z}_{s r r}=Z_{s}+\frac{a}{2} \dot{\alpha}+\frac{b}{2} \dot{\theta}$

$Z_{\text {srl }}=Z_{s}+\frac{b}{2} \alpha-\frac{a}{2} \alpha$

$\dot{Z}_{s r l}=Z_{s}+\frac{b}{2} \dot{\alpha}-\frac{a}{2} \dot{\alpha}$

$Z_{s f}=Z_{s}-\frac{b}{2} \alpha$

$\dot{Z}_{s f}=Z_{s}-\frac{b}{2} \dot{\alpha}$

where $Z_{s}=$ displacement at centre of the engine, $\alpha=$ pitch angle, $\theta=$ roll angle, $\dot{\alpha}=$ pitch rate and $\dot{\theta}=$ angle rate. Overall equations for the three engine mounting system can be summarized as follows: 
1. Summation of force in vertical direction with pitch and roll motion

$$
\begin{gathered}
-K_{R R}\left(Z_{s}+\frac{a}{2} \alpha+\frac{b}{2} \theta\right)-C_{R R}\left(Z_{s}+\frac{a}{2} \dot{\alpha}+\frac{b}{2} \dot{\theta}\right)-K_{R L}\left(Z_{s}+\frac{b}{2} \alpha-\frac{a}{2} \alpha\right) \\
-C_{R L}\left(Z_{s}+\frac{b}{2} \dot{\alpha}-\frac{a}{2} \dot{\alpha}\right)-K_{F}\left(Z_{s}-\frac{b}{2} \alpha\right)-C_{F}\left(Z_{s}-\frac{b}{2} \dot{\alpha}\right)-F(t) \\
=m \ddot{Z}_{s}
\end{gathered}
$$

2. Summation of moment in pitch direction with pitch and roll motion

$$
\begin{gathered}
{\left[-K_{R R}\left(Z_{s}+\frac{a}{2} \alpha+\frac{b}{2} \theta\right)-C_{R R}\left(Z_{s}+\frac{a}{2} \dot{\alpha}+\frac{b}{2} \dot{\theta}\right)-K_{R L}\left(Z_{s}+\frac{b}{2} \alpha-\frac{a}{2} \alpha\right)\right.} \\
\left.-C_{R L}\left(Z_{s}+\frac{b}{2} \dot{\alpha}-\frac{a}{2} \dot{\alpha}\right)-K_{F}\left(Z_{s}-\frac{b}{2} \alpha\right)-C_{F}\left(Z_{s}-\frac{b}{2} \dot{\alpha}\right)\right]\left(\frac{b}{2}\right)+F(t) e \\
=I_{p} . \ddot{\alpha}
\end{gathered}
$$

3. Summation of moment in roll direction with pitch and roll motion

$$
\begin{gathered}
{\left[-K_{R R}\left(Z_{s}+\frac{a}{2} \alpha+\frac{b}{2} \theta\right)-C_{R R}\left(Z_{s}+\frac{a}{2} \dot{\alpha}+\frac{b}{2} \dot{\theta}\right)-K_{R L}\left(Z_{s}+\frac{b}{2} \alpha-\frac{a}{2} \alpha\right)\right.} \\
\left.-C_{R L}\left(Z_{s}+\frac{b}{2} \dot{\alpha}-\frac{a}{2} \dot{\alpha}\right)\right]\left(\frac{a}{2}\right)+F(t) f \\
=I_{R} \ddot{\Theta}
\end{gathered}
$$

where $K_{R R}=$ stiffness value for spring at rear right, $C_{R R}=$ damping value for damper at rear right, $K_{R L}=$ stiffness value for spring at rear left, $C_{R L}=$ damping value for damper at rear left, $K_{F L}=$ stiffness value for spring at front and $C_{F}=$ damping value for damper at front.

\subsection{Experimental Setup of Engine Mounting System}

In order to validate the three mount engine mounting system model, an experiment was setup using Toyota Diesel Engine Test Bed at UPNM. Four accelerometers were installed to obtain the vehicle's vertical acceleration at three engine mount location and center of engine as shown in Fig. 15 and 16. Fig. 15a shows the whole experimental setup in this research while Fig. 15b, 16a, 16b and 16c show the exact location of the accelerometers. The accelerometers have been located at the center of the engine, rear right, left right and front mount in order to capture vibrational effect of the engine to the engine mount. The 4 single axis accelerometers from Kistler (Type: 8315A010ATTA00) has been connected to data acquisition from Measurement Computing Corporation (MCC DAQ, USB-1408FS) to log out the acceleration response into the software. 


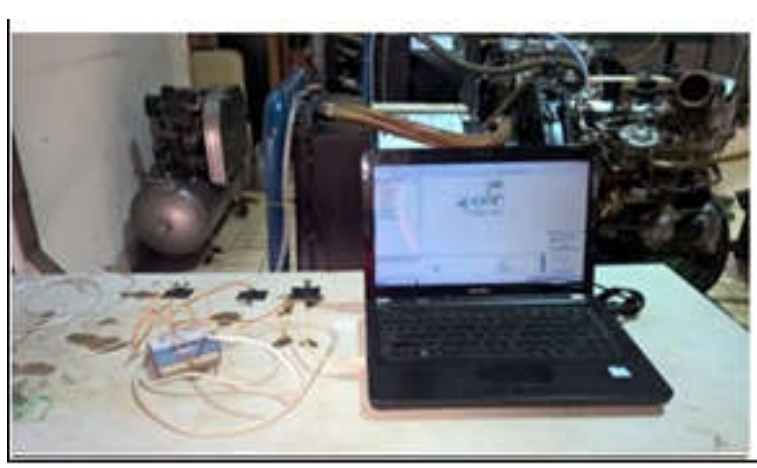

a

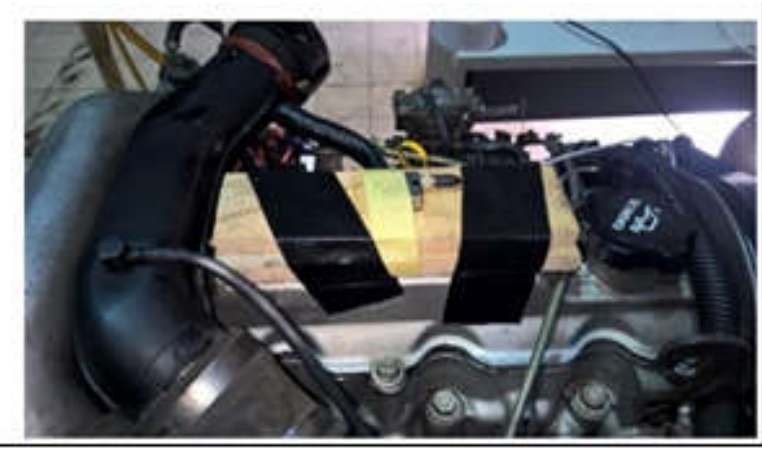

b

Fig.15. a) Whole experimental setup b) accelerometer (at center of engine)

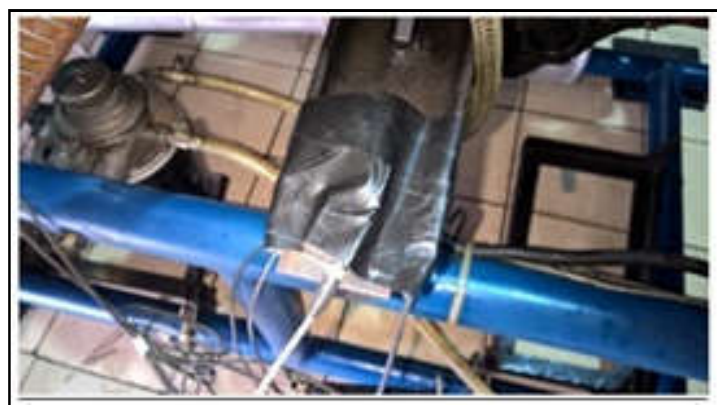

c

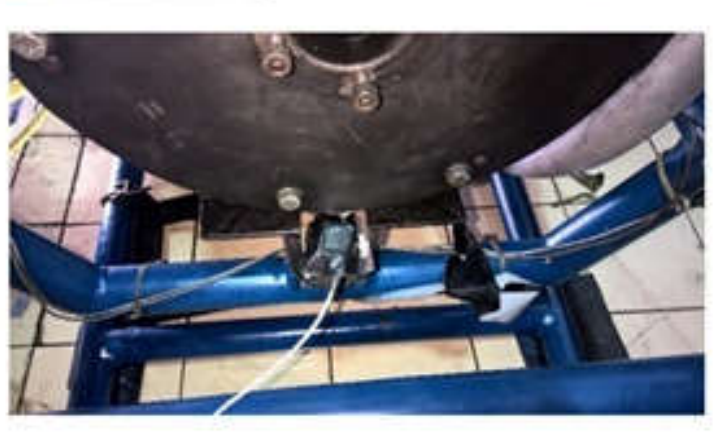

e

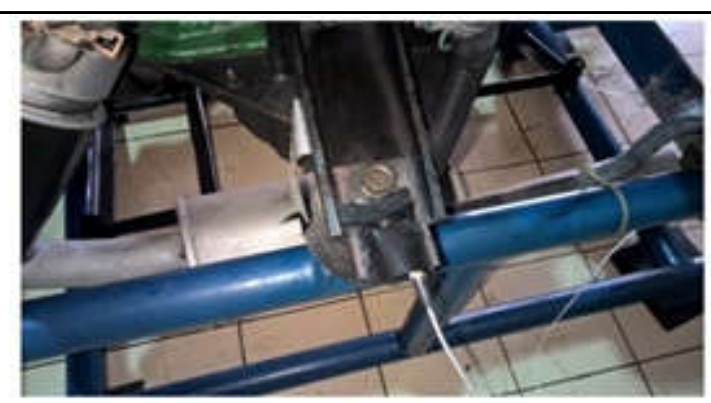

d

Fig.16. Accelerometer at three engine mount location c) rear right d) rear left e) front A type of graphical user interface software namely Dasylab has been deployed for real time acquisition interface. The accelerometer has been connected to 4 channel input output of MCCDAQ and the result has been displayed and saved in the Dasylab software system.In this experiment, the time taken was setting for 30 seconds for each test and all four acceleration response will be captured simultaneously by the software. A schematic diagram of the experimental setup can be shown as in Fig. 17. 


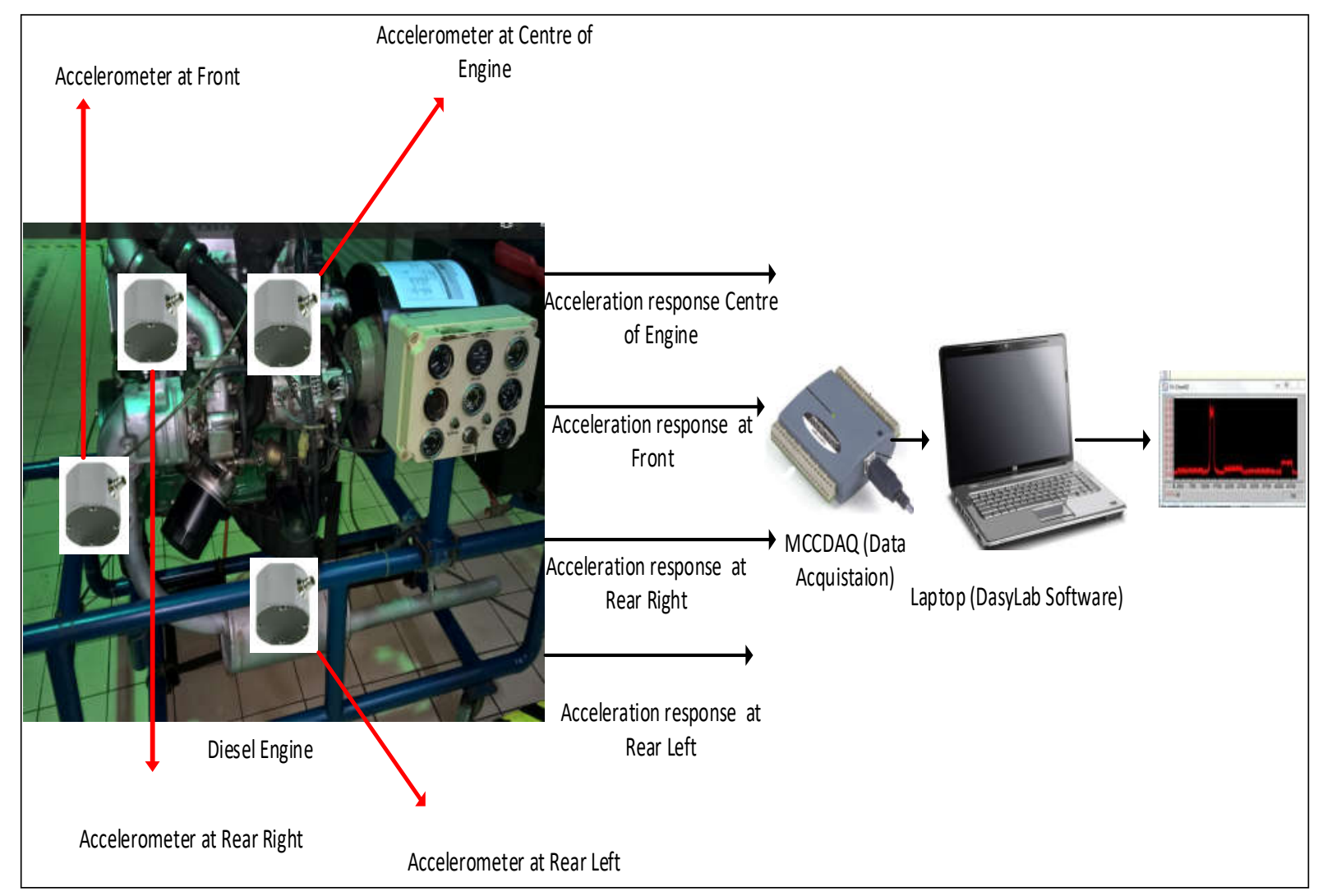

Fig.17.Schematic diagram of the experimental setup

This experimental section can be divided into subsections, the contents of which vary according to the subject matter of the article. It must contain all the information about the experimental procedure and materials used to carry out experiments.

\section{CONCLUSION}

An engine mount equation for a three degree of freedom system has been derived using Newton Second Law and implemented in Simulink MATLAB in order to evaluate the behaviour of the system. The behaviour of the system has been evaluated by comparing the acceleration response with the actual engine mount system. Four accelerometers have been used and located at the engine mount as well as the engine center of gravity. This proposed model is proven simple, able to capture the behavior of three degree of freedom of engine mount system and also can avoid the complexity during modelling. The results show that the behavior of the proposed model has good agreement with the behavior of the real passive engine [23] mount system. 


\section{ACKNOWLEDGEMENTS}

We would like to thank National Defense University Malaysia for the all relevant equipment and facilities provided during this research.

\section{REFERENCES}

[1] Yan W B, Jiang S Z, Cai Y J, Wen L Z, Chen Y. Experimental study of engine mount system's vibration characteristics. In IEEE WRI World Congress on Software Engineering, 2009, pp. 43-46

[2] Deng Z X, Zheng L. vibration control and design of vehicle engine mount activated by magnetorheological fluid. Advanced Engineering Forum, 2012, 2:1077-1081

[3] Hosseini A M. A solenoid-based active engine mount: Modelling, analysis verification. British Columbia: Simon Fraser University, 2010

[4] Zhang Q, Jin X, Peng W. A non-linear finite element analysis of car engine mounting system rubber components. In 2nd IEEE International Symposium on Computational Intelligence and Design, 2009, pp. 132-135

[5] Wijaya A A, Darsivan F J, Solihin M I, Akmeliawati R. Terminal sliding mode control for active engine mounting system. In IEEE/ASME International Conference on Advanced Intelligent Mechatronics, 2009, pp. 417-420

[6] Cheli F, Pezzola M, Agostoni S, Giombini M. Methodology to optimize engine mounts design in order to minimize inertial unbalances vibration propagation. In 19th IEEE Mediterranean Conference on Control and Automation, 2011, pp. 922-927).

[7] Elahinia M, Ciocanel C, Wang S. MR-and ER-based semiactive engine mounts: A review. Smart Materials Research, 2013, 1:1-21

[8] De Silva C. W.Vibrations fundamentals and practice. Florida: CRC Press, 2000

[9] Yu Y, Naganathan N G, Dukkipati R V. A literature review of automotive vehicle engine mounting systems.Mechanism and Machine Theory, 2001, 36(1):123-142

[10] Rasekhipour Y, Ohadi A. Evaluating vibration performance of a semi-active MR engine mount.In 2nd IEEE International Conference on Control, Instrumentation and Automation, 2011, pp. 90-95 
[11] Gennesseaux A. Research for new vibration isolation techniques: From hydro-mounts to active mounts. SAE Technical Paper 931324, 1993

[12] Fakhari V, Choi S B, Cho C H. A new robust adaptive controller for vibration control of active engine mount subjected to large uncertainties. Smart Materials and Structures, 2015, 24(4):45-54

[13] Olsson C. Active automotive engine vibration isolation using feedback control. Journal of Sound and Vibration, 2006, 294(1):162-176

[14] Fakhari V, Ohadi A. Robust control of automotive engine using active engine mount. Journal of Vibration and Control, 2013, 19(7):1024-1050

[15] Liang T, Liang T, Shi W. Study on electromagnetic actuator active engine mount with fuzzy control.In IEEE International Conference on Mechatronics and Automation, 2009, pp. 3010-3014

[16] Darsivan F J, Martono W, Faris W F. Active engine mounting control algorithm using neural network. Shock and Vibration, 2009, 16(4):417-37

[17] Yuyou L. Semi-active damping control for vibration isolation of base disturbances. Phd thesis, England: University of Southampton, 2004

[18] Feyzi T, Esfahanian M, Tikani R, Simulation of the dynamic behavior of the magnetorheological engine mount for automotive applications.International Journal of Automotive Engineering, 2011, 1(2):1-8

[19] Segla S, Kajaste J, Keski-Honkola P. Optimization of semi-active seat suspension with magnetorheological damper. In J. Náprstek, J. Horáček, M. Okrouhlík, B. Marvalová, F. Verhulst, \& J. Sawicki(Eds.), Vibration problems. Dordrecht: Springer, 2011, pp. 393-398

[20] Acocella G, Anchini R, Paciello V, Pietrosanto A, Sommella P. A new approach to magnetorheological damping control. In IEEE Instrumentation and Measurement Technology Conference, 2010, pp. 908-912

[21] Warminski J, Kecik K. Autoparametricvibrations of a nonlinear system with a pendulum and magnetorheological damping. In J. Warminski, S. Lenci, M. P. Cartmell, G. Rega, \&M. Wiercigroch (Eds.), Nonlinear dynamic phenomena in mechanics.Amsterdam: Springer Science+Business Media, 2012, pp. 1-61 
[22] Foumani M S, Khajepour A, Durali M. Optimization of engine mount characteristics using experimental/numerical analysis. Modal Analysis, 2003, 9(10):1121-1139

[23] Mohd N K, Moumen I, Muhammad I A, Zairi I R.Computational analysis of air intake system for internal combustion engine in presence of acoustic resonator. ARPN Journal of Engineering and Applied Sciences, 2015, 10(20):9468-9475

\section{How to cite this article:}

Yusoff M F M, Hudha K, Kadir Z, Rao V, Ameer N H, Ishak S A F M. Modelling and verification of three dof engine mount system. J. Fundam. Appl. Sci., 2017, 9(3S), 395-416. 